\title{
PESQUISANDO NO PERIGO: ETNOGRAFIAS VOLUNTÁRIAS E NÃO ACIDENTAIS*
}

Alba Zaluar

\section{Relativismo cultural na nova ordem mundial}

A questão do relativismo cultural, importante elemento na perspectiva teórica da Antropologia porque baseado no entendimento do outro, assume caráter polêmico na passagem do milênio ou do século XX para o XXI. O dissenso dentro da disciplina apareceu na forma de fusão ou não de horizontes, de permanência ou não do hiato entre interlocutores que não se confundem nem entram em completo acordo, mas principalmente no que fazer diante dos dilemas postos pelos novos sujeitos-objetos e dos impasses advindos da difusão planetária de posturas universalistas, como a dos direitos humanos.

O que fazer com o relativismo cultural diante da globalização da economia e dos meios de comunicação, do ecoturismo, do aparecimento de nações modernas entre os povos ditos tribais, e da crítica da modernidade em casa? Novos problemas, novas perplexidades, novos dilemas apresentaram-se para o antropólogo. Os nativos são agora cidadãos de seus respectivos países, muitos deles transformados em nativos antropólogos de seus povos, historiadores de sua história, filósofos de seu modo de encarar o mundo.

Geertz (1988) aponta as novas dúvidas, algumas tratadas com ironia. É decente? Quem somos nós para descrevê-los? É ético ou politicamente correto? Lamenta o abandono das velhas questões: o que é evidência, como ela é coletada, como palavras se ligam ao mundo, textos à experiência, obras à vida? Reclama do abandono da mimesis, da representação e da objetividade, também preocupações do crítico literário, como efeito deletério dos desconstrutivistas que atacaram a própria língua como fascista e tirânica. Neste paradigma, a etnografia seria como um discurso sem referente, portanto, aberto à licença poética, antes privilégio dos artistas, agora reino também dos que abandonam o realismo que guiava os primeiros etnógrafos para exercitarem a criatividade em remontar outros mundos, outros pensares, outros fazeres. Este exercício, de uma reação à língua encarcerada em 
uma casa-prisão, levou a etnografia a uma situação-limite, um beco sem saída da disciplina.

O dilema não estaria apenas nos problemas de tradução da cultura nativa, tradicional, tribal ou antiga para a cultura da qual faz parte o antropólogo - uma cultura contemporânea, moderna ou pós-moderna — baseada hoje em universalismo não centrado no sujeito ocidental, mas devedora da tolerância à diferença e do respeito aos direitos do outro. No estudo dos novos objetos urbanos, como relativizar quando a "cultura" em questão é considerada juridicamente fora da lei e moralmente inaceitável pelos que fazem parte da mesma parcela da população, da mesma classe social, da mesma vizinhança? Poder-se-iam tratar os criminosos que passaram a agir cada vez mais violentamente, até mesmo contra seus vizinhos e iguais, como uma cultura autônoma, ou como meros marginais ou desviantes, do mesmo modo que usuários de drogas, contestadores, ou pessoas que adotam estilos não-conformistas de vida? Mas, afinal, haveria um lugar para o fazer antropológico, neste caso limite, um estudo de predadores de outras pessoas, vítimas e vizinhos?

As respostas são várias. Novas culturas ou redes globalizadas ultrapassam as sociedades nacionais e estão no mundo necessitando de registro, conhecimento e entendimento. Sociedades nacionais estão cada vez mais híbridas ou diferenciadas internamente, abrigando muitas culturas, subculturas ou estilos, também precisando de registro e interpretação. Novos temas, tais como etnicidade urbana, redes de tráficos transnacionais, relações sociais na Internet, situações teatrais entre desconhecidos nas cidades, ocuparam as mentes (e os corações) dos antropólogos.

Talvez o mais espinhoso de todos os dilemas atuais do fazer antropológico seja o dos direitos humanos no mundo globalizado, cheio de intervenções e trocas interculturais, mas com exemplos frequentes de violações aos direitos de minorias étnicas ou de gênero dentro dos novos países que foram surgindo após o fim dos impérios coloniais. O que fazer quando nativos fora da situação colonial oprimem outros povos em regimes autoritários, fazem guerras de extermínio, ou por causa da limpeza étnica, ou em nome do fundamentalismo religioso? Como interpretar a discriminação religiosa, lá e cá, e a negação absoluta da verdade do outro? Deve silenciar-se sobre tais violências por causa da perspectiva relativista da disciplina?

Outras perguntas se colocam, pois, para o antropólogo: é possível estudar os nativos em vários países de fronteiras artificiais, mas defendidas a ferro e fogo pelas armas nas guerras étnicas e nos fundamentalismos religiosos? Ao revelar o fundamentalismo islâmico, é possível criticar simultaneamente o fundamentalismo cristão que tanto estrago faz entre nós e no mundo todo? 
Ao estudar os envolvidos no tráfico de drogas ilegais, movidos diferentemente pela busca de altos lucros, pelo poder conseguido pelo uso constante de armas de fogo e pela atração que o dinheiro e a arma exercem sobre as mentes mais frágeis dos jovens e das mulheres, é possível deixar de exercer a crítica cultural, da qual não se eximiram etnógrafos que consolidaram a disciplina, e falar da crueldade de suas ações e da destruição que os cerca?

Antropólogos também passaram a estudar nativos racistas, supremacistas brancos em sua casa, como na África do Sul. Do mesmo modo, nativos localmente sediados, conectados com tráfico internacional de drogas ilegais e adeptos dos seus métodos violentos de solucionar conflitos e disputas, tornaram-se objetos de curiosidade etnográfica. Como operar os princípios do relativismo cultural sem deixar de apresentar todos os efeitos maléficos para coletividades civis, nas quais traficantes vivem sem compartilhar inteiramente suas práticas sociais, principalmente as limitadas por valores morais, práticas que tais empreendimentos econômicos ilegais trazem? Não resta dúvida de que novos problemas e dilemas éticos, por vezes dilacerantes, se antepuseram ao fazer antropológico: o que são direitos humanos e qual o seu alcance entre nativos não-ocidentais; quem conta como pessoa humana e quem deve ser ouvido(a) dentro das sociedades estudadas; como lidar com a opressão de pessoas no interior das "sociedades dos nativos" quando os opressores são também nativos?

As concepções relativistas da disciplina seriam justificativas suficientes para negar os direitos universais, conquistas da humanidade desde o século XVIII e que foram ampliados pouco a pouco para incluir direitos indígenas, direitos coletivos, direitos de minorias religiosas, sexuais, étnicas? Ora, tais direitos fazem parte de uma cultura globalizada e invadem os espaços culturais em todo o planeta com a mesma rapidez de outras manifestações culturais. Não é possível ignorá-los em nome de uma uniformidade cultural inexistente desde sempre. Claro que essa difusão acentuou conflitos internos, deu-lhes nova argumentação e legitimidades, antes nunca ou pouco usadas.

O antropólogo não pode se calar sobre o tratamento dado a refugiados, estrangeiros ou desclassificados nas novas unidades políticas artificiais da África, nem aos "inimigos" dentro de uma favela em alguma cidade brasileira. As lógicas do confronto guerreiro, da ideologia do terror ou da guerra molecular, fenômenos mundiais que se manifestam em variados e pequenos recantos deste vasto planeta, operam pela desumanização do inimigo ou dos dissidentes, o que justificaria as atrocidades cometidas contra eles nos cinco continentes por razões e processos diferentes. Contudo, como afirmaram os fundadores da disciplina, não se pode deixar de levar em consideração o 
que pensam as pessoas afetadas por tais violências e violações. A elas cabe a última palavra, que são múltiplas, sobre o que acontece, onde, como, por quem e por quê.

No que tange a estudos de grupos que fazem parte de sociedades maiores, especialmente grupos não compostos de forasteiros, desviantes ou dissidentes, mas de criminosos fora da lei, a aplicação das concepções relativistas da disciplina também gera problemas na medida em que muitos discordam de o relativismo cultural ser também moral (Zaluar 1994). Isto quer dizer que, quando se trata de moralidades que provocam vítimas em outros setores da mesma sociedade inclusiva, todo o cuidado é pouco no uso da relativização.

Em trabalho de campo etnográfico bem-feito deve estar registrado o tratamento dado aos "inimigos", localmente chamados de "alemães", dentro de uma favela em alguma cidade brasileira, narrando inclusive as atrocidades cometidas contra eles, assim como a fala dissidente dos vizinhos de traficantes, aterrorizados por eles e pelos policiais violentos. Só desta forma será possível entender a constelação de práticas sociais mais do que violentas, belicosas e cruéis, como parte da construção de uma identidade masculina guerreira, assim como os dois poderes despóticos que tornaram o viver nas favelas tão cheio de perigos e sofrimentos atrozes. Diante deles, ouvindo-os falar sobre esses sofrimentos, o pesquisador não pode se restringir a registrar a cultura diferente dos traficantes ou a dos policiais violentos.

\section{Desbravando o terreno}

Ocupei grande parte dos meus textos nos últimos 25 anos em dissecar o caráter organizado/ desorganizado da criminalidade contemporânea, usando principalmente, mas não só, o material resultante do trabalho de campo etnográfico. Nesse percurso, enfrentei muitos estágios de dúvidas, curiosidades, interpretações e explicações para o que foi se constituindo como um dos maiores problemas coletivos, segundo a percepção dos habitantes deste país. O trajeto foi longo e nele fui transformando a minha identidade profissional.

Quando comecei, não havia reflexão sobre a pesquisa no meio do perigo e da violência nas cidades brasileiras. Acrescentei minhas experiências anteriores a este fazer antropológico que, mesmo em novo contexto carregado de ciladas e riscos, é ofício, exercício e arte de se aproximar para conhecer e se afastar para entender, dois movimentos imprescindíveis para garantir um mínimo de objetividade do pesquisador e acesso à subjetividade dos pesquisados. 
Sempre considerei que a aventura de conhecer outros mundos simbólicos é uma via de mão dupla da subjetividade e da objetividade. É preciso navegar em vários mares ao mesmo tempo, como Malinowski (1975) se referia ao trabalho etnográfico, real e metaforicamente, ou jogar simultaneamente em vários tabuleiros, como os gregos nos tempos trágicos (Vernant 1992). Isto também quer dizer que o pesquisador de campo é ao mesmo tempo ator, nas diversas situações de pesquisa, e autor, quando monta o projeto, quando faz perguntas, quando escreve com os fragmentos que recolheu. Alguns pós-modernos afirmam até que esta condição de ator e de autor deve estar sempre clara quando etnógrafos escrevem sobre as suas experiências alhures, que é ela a narrativa etnográfica (Clifford 1986; Marcus \& Fischer 1986).

Mas há novos problemas decorrentes do emaranhado de trocas econômicas, culturais e políticas que marcam o mundo cada vez mais globalizado hoje. Nas aproximações com os sujeitos da pesquisa que eu procurava conhecer, vários dilemas éticos e demandas práticas, algumas cercadas de perigo real, foram surgindo sem que houvesse, como agora, uma reflexão sobre elas. Ao longo dos afastamentos para entender, fui acrescentando doses cada vez mais altas de sociologia, ciência política, economia, psicologia. No processo, virei também colecionadora de material secundário: arquivos de recortes de jornais, filmes, estatísticas oficiais sobre o aumento da criminalidade (um poderoso indicador da atividade organizada, porém muito conflitiva do crime-negócio). Uma bricoleuse que junta fragmentos sem um projeto, sem saber exatamente o uso que se vai dar a eles, mas intuindo que um dia servirão. Preenchiam os vazios deixados entre os fragmentos das falas dos entrevistados, elos de uma cadeia que teve que ser refeita com outros dados, inclusive estatísticos, para que os sentidos não ficassem restritos ao senso comum, aos horizontes limitados, com pontos cegos inevitáveis. A razão para isto estava no próprio objeto empírico, ou seja, no estado da arte dos estudos e das investigações policiais e jornalísticas sobre o tráfico de drogas ilegais.

Na delimitação do objeto empírico deste tráfico, depende-se do que já foi previamente mapeado em outras investigações feitas pelos agentes institucionais encarregados de vigiá-los e reprimi-los, assim como da repercussão dos casos na imprensa. Diante das falhas e da falta de recursos nos setores da inteligência institucional e da polícia investigativa, existe ainda pouco conhecimento no Brasil sobre as dinâmicas e os fluxos dos vários tipos de tráfico de drogas ilegais abundantes no país. Por isso, continua muito difícil pesquisar o grande banditismo no Brasil. Os grandes bandidos ainda não são investigados com o mesmo empenho que os bandidos 
de menor calibre, nem tampouco julgados e condenados. Os registros de suas atividades ilegais estão dispersos na imprensa, mas não há arquivos oficiais disponíveis para o pesquisador, visto que processos judiciais correm em segredo de justiça e o acesso à documentação existente no Ministério Público e no Judiciário está cercado de complicadas operações burocráticas e decisões políticas.

Isto quer dizer que, para a maior parte dos pesquisadores acadêmicos, afora os privilegiados que têm contatos com a Polícia Federal ou o Ministério Público, resta o fado de continuar estudando os jovens delinquentes de vizinhanças pobres, os pobres condenados que povoam as prisões brasileiras, os arrependidos ou defroqués de quadrilhas e comandos, dentro e fora da prisão, que só muito raramente resolvem abrir a boca para contar o que sabem. A lei do silêncio tem, de fato, enorme peso nesses locais, não excluindo ninguém envolvido: moradores, funcionários governamentais e não-governamentais, policiais, milícias. Nada mais adequado para romper a barreira da lei do silêncio do que a pesquisa etnográfica, que se monta na confiança entre entrevistador e entrevistado. Mas ela tem que estar solidamente baseada na ética de garantir o anonimato e o sigilo sobre quem disse o quê. A investigação de campo não tem os objetivos, os métodos e a ética da investigação policial.

Apesar de admitir a importância da experiência multidisciplinar e do apreço pela variedade de fontes e materiais, considero o fazer antropológico imprescindível como metodologia de trabalho de campo, além de ser o que mais apresenta armadilhas ao pesquisador na interação face a face com os que violam leis de modo sistemático, porque o crime faz parte de suas vidas cotidianas. Estou me referindo, claro, a criminosos de carreira, ou seja, os que já abraçaram o crime como modo de vida, ou àqueles que estão no processo de entrar nesta carreira de modo quase natural, sem a necessidade de uma opção ou um projeto. A maior parte dos jovens entrevistados nas várias pesquisas da minha equipe, feitas ao longo desses 28 anos, apresentava-se como quem foi entrando ou sendo levado sem nem saber muito bem por que, sempre afirmando que "ninguém me obrigou não, fui por mim mesmo". Tal afirmação da independência de um sujeito que não conhece os limites sociais, independência esta tão importante na construção da identidade hipermasculina ou da insubmissão incondicional, é o extremo oposto da docilidade tão criticada pelos que os defendem, relativizando como se constituíssem uma cultura singular, consensual e autônoma. De fato, nessa construção da masculinidade, trata-se de negar qualquer proximidade ou conexão com o feminino, outro nome da docilidade (Zaluar 1994). 


\section{Que etnografia é a mais apropriada e a menos arriscada?}

O trabalho de campo etnográfico, baseado na observação participante segundo esta abordagem, é o modo de conhecer a "sociedade" ou a "cultura" estudada que culmina na sua reconstituição desde o ponto de vista do nativo. Isto é importante para que os aspectos subjetivos, do psiquismo ou do "espírito nativo" (Malinowski 1975), sejam incorporados às regularidades objetivas da estrutura social.

Para alguns pioneiros da disciplina, radicais da aproximação, o trabalho de campo havia sido pensado como mergulho do antropólogo no mundo do outro que ele quer conhecer, o que acaba por diluir as fronteiras e as distinções entre um e outro. Muitos mergulham tanto que o próprio antropólogo se transforma radicalmente em um processo quase de conversão para a cultura estudada, seja ela uma religião, um grupo étnico e, mais recentemente, um grupo criminoso (Rodgers 2007). As posições mais conhecidas desta postura foram as de Roger Bastide, que afirmou africanus sum (sou africano) no seu texto sobre os fiéis do candomblé nagô da Bahia e advogava "virar nativo" para entender profundamente o que estes pensavam e sentiam. Esta perspectiva, muito apreciada pelos populistas, baseou-se na empatia, na simpatia, na sentimentalidade da compaixão e, até mesmo, na identificação mística com os nativos. Os etnólogos que estudaram tribos primitivas poderiam até se considerar "adotados" ou socializados como crianças na cultura tribal, mas tiveram consciência de que seriam sempre outros, estrangeiros. Passar pelos rituais de iniciação ou submeter-se a liturgias de cargos de poder foram operações de inclusão que poucos antropólogos realizaram, quase restritas aos que estudaram religiões não-ocidentais.

Além de todos os problemas práticos e éticos aos quais a inserção na sociedade estudada pode levar, esta inclusão, em última análise, significaria negar o lugar do observador e, portanto, qualquer objetividade. Ficaria apenas a participação no binômio da observação participante.

Quando esta postura foi trazida para o estudo de grupos criminosos no contexto urbano contemporâneo, chegou-se aos imponderáveis da vida real de forma trágica. Fazer parte de gangues, pandillas, galeras ou quadrilhas, submetendo-se aos seus rituais de iniciação e às exigências de participação em atividades criminosas, colocou os antropólogos-participantes em dilemas éticos insolúveis: para ser aceito por eles e entendê-los, o antropólogo teria que aceitar participar de suas atividades criminosas como parceiro, podendo ser julgado, condenado e preso como qualquer criminoso.

Em Carnal Sociology, Loïc Wacquant (2004:vii-viii) defende que o melhor meio de pesquisar é a imersão iniciatória e a conversão para vivenciar as 
mesmas práticas dos grupos estudados, neste caso, um grupo de boxeadores negros de um gueto americano, mas que foi tomado como modelo no estudo de grupos criminoso. Diz ele: ${ }^{1}$

[...] não há nada melhor do que a imersão iniciatória e até mesmo a conversão moral e sensual para o cosmos sob investigação... Isto permite que o sociólogo se aproprie na e pela prática dos esquemas cognitivos, estéticos e éticos que aqueles que habitam este cosmos executam nas suas ações cotidianas.

A imersão na prática de criminosos foi de fato vivida perigosamente por alguns estudiosos de gangues norte-americanas e latino-americanas. Jeff Farrell e Mike Hamm (1998) enumeraram algumas das aventuras e desventuras vividas por pesquisadores que pretendiam, mesmo lidando com grupos fora da lei, seguir os cânones da disciplina quanto à aproximação e à absorção da cultura do outro. Dennis Rodgers (2007:456), inspirado em Loïc Wacquant, narra como vivenciou a iniciação e a imersão em uma pandilla (gangue) na Nicarágua, imersão que apresentou como uma astúcia para ficar mais seguro e ser mais respeitado em uma cidade violenta, mas que teve outros efeitos: ${ }^{2}$

[...] ao tornar-me membro da gangue, eu era frequentemente forçado a adotar, ou se esperava que eu adotasse, um número de padrões de comportamentos particulares, alguns dos quais eram de fato compostos pelo meu ser chele quadrilheiro... Isto incluía ter que participar de uma gama de ações violentas e ilegais, inclusive guerras entre gangues, roubos, brigas, espancamentos, lutas esportivas e conflitos com a Polícia, cujo resultado foi me submeter a uma série de coisas que eu poderia ter evitado, inclusive ser atacado, ameaçado, espancado, esfaqueado, alvo de tiros e atirado de um carro em movimento.

O mais interessante deste texto é que chele, segundo o autor, significa europeu e estrangeiro, ou seja, apesar de se considerar incluído como membro da quadrilha ao participar de suas atividades ilegais, o pesquisador nunca deixou de ser tido como estrangeiro pelos demais comparsas. Mesmo assim, reafirmou que deveria participar das ações criminosas da gangue.

As conclusões metodológicas a que cheguei foram bem diferentes destas e tomei outros rumos mais condizentes com a perspectiva de que o pesquisador continua sendo estrangeiro e, portanto, nunca deixam de existir diferenças culturais, éticas e morais que o distanciam dos sujeitos de sua pesquisa.

A questão teórica básica está no fato de que tais estudos não rompem com a ideia de que "cultura" ou "sociedade" refere-se a unidades delimita- 
das, com homogeneidade e consenso internos que permitem falar apenas de algumas regularidades encontradas entre os conflitos, as divergências e as incoerências que fazem parte da dinâmica cultural e social. Como sempre encontrei a polifonia, as divergências, as incoerências e os conflitos no contexto urbano, assim como etnólogos que estudaram os processos sociais de mudança em algumas sociedades tribais, os conceitos de "cultura" e "sociedade" foram por mim substituídos pelo foco nas redes, nas disputas, na dinâmica da formação e da transformação de grupos, quase-grupos e redes, bem como nas subjetividades diversas.

Quadrilhas, gangues e galeras existem em vizinhanças que abrigam outras formas de associação, outros valores e outras práticas com as quais estão em divergência, ou até mesmo conflitos belicosos, mas em permanente contato. Não devem ser abordadas como tribos primitivas com padrões culturais abrangentes e com grau de autonomia reconhecível, ou até mesmo como sociedades parciais, tal como sociedades camponesas. Em outras palavras, para parafrasear os estudos de campesinato, grupos de criminosos são uma part society de outra part society, ou uma subcultura de outra subcultura, incluídas em vizinhanças, bairros, classes sociais, unidades maiores identificáveis não pela homogeneidade cultural, mas pela diversidade e pela existência de um Estado em um país com fronteiras geográficas definíveis. É impossível não considerar os efeitos jurídicos e os julgamentos morais que cercam as atividades criminosas dos sujeitos que continuam a pertencer a redes sociais mais amplas, locais ou não, e a interagir com outras pessoas em contextos sociais dentro e fora do mundo do crime, pois isto será parte dos seus egos (selves) sociais.

Porém, muito antes de essas desventuras dos pesquisadores do crime serem registradas em letra de forma, Evans-Pritchard (1951) já havia denunciado tal postura como a do argumento if I were a horse, a ser evitada em qualquer pesquisa de campo etnográfico. No seu engano, o etnógrafo imaginaria que poderia pensar, sentir e agir como se fosse um cavalo para entendê-lo. O mesmo argumento poderia ser empregado no estudo de loucos, doentes, leprosos e criminosos de vários tipos. Por isso, Geertz (1988), refletindo sobre suas manifestações mais atuais, afirma que esta transformação da pessoa do antropólogo é impossível, pois terminaria na mera descrição imaginária daquilo que os nativos, tomados como coletividade homogênea, una e consensual, pensam e sentem - uma descrição do antropólogo, visto que não existe esta sociedade consensual. Caracterizei-a como a miopia etnográfica que impede a visão de longe.

Aceitei que a observação participante é impossível para estudar grupos mais ou menos organizados de criminosos de carreira, e fiquei com a 
observação, abandonando a participação, pelo menos nas ações violentas e criminosas que os sujeitos da pesquisa praticavam como meio de vida. No entanto, a abordagem qualitativa continuou sendo privilegiada, visto que, por meio de entrevistas aprofundadas e outras técnicas, é possível compreender as disposições, os valores e os motivos que os levam a praticar crimes, ou seja, é possível considerar a dimensão da subjetividade dos pesquisados. As conclusões a que cheguei sobre a dinâmica dos conflitos violentos entre os grupos juvenis criminosos não foram muito diferentes daquelas a que chegaram os antropólogos que se iniciaram neles, sem ter me tornado membro da quadrilha ou da galera, apenas utilizando as técnicas de entrevistas e de grupos focais. O mesmo hermeneuta Geertz (1983) afirmava que o antropólogo não tem que recorrer a uma capacidade sobre-humana de autonegação do seu ego ou de co-sentimentalidade com os estudados, porém simplesmente ser aceito como parceiro em conversações para reconstituir os sentidos da cultura local que estuda.

Entre os problemas práticos de pesquisar no meio do perigo, fugindo do tiroteio, driblando omissões, dissimulações e mentiras de quem tem que esconder suas atividades ilegais, está, pois, o da identidade que assumirá o pesquisador. Não se pode ser nem infiltrado (o que equivaleria a decretar a própria morte), nem iniciante (ardil posto ao que quer se tornar nativo e que pode levá-lo a problemas com a lei, já apontados com regularidade na literatura citada, ou na própria morte do antropo-traficante principiante ou antropo-assaltante de primeira viagem).

\section{A etnografia não acidental e a ética do viajante mediador}

Afora a primeira incursão em Cidade de Deus em 1980, quando acabei estudando inesperadamente a quadrilha de Manoel Galinha e Ailton Batata, as demais pesquisas que realizei sobre grupos criminosos não podem ser consideradas "etnografias acidentais" ou "pesquisas involuntárias" (Rodgers 2007). Adotei, por isso, o trabalho de campo como viagem propositada ou passagem de um mundo para o outro. $\mathrm{O}$ antropólogo como viajante procura conhecer previamente o seu campo e se prepara como pode para ele. Não que surpresas estejam suprimidas, mas "saber entrar" e "saber sair" são procedimentos fundamentais para realizar o vai-vem da postura antropológica, permanecendo outro e conhecendo o nativo para conhecer-se melhor na diferença. Participar e observar, ser de lá e estar cá, registrar lá e escrever cá, ouvir teorias e conceitos nativos e pensar conceitos e teorias antropológicas são, portanto, tensões que nunca se desfazem, nem quando se pesquisam criminosos de vários calibres. 
O mais interessante nesta perspectiva é que o antropólogo viajante passa de um mundo ao outro e acaba sendo, por meio do seu texto, uma ponte entre os dois mundos. Como pertence a um e conhece o outro, traduz, interpreta e explica o outro para o um. Nos seus textos, criaria mapas simbólicos do outro mundo no qual foi um viajante, mas não um turista acidental. Mais que um mero broker, um intermediário entre culturas diferentes, o antropólogo vira momentaneamente um marginal que não pertenceria nem a uma nem a outra, estando na passagem entre elas. Sendo assim, ele junta mundos invisíveis um ao outro, diminuindo a cegueira cultural e a arrogância étnica que os separam ainda mais do que a diferença, porque alimenta o ódio e o ressentimento. O ofício do etnógrafo ajuda a destruir as construções simbólicas feitas para criar imagens negativas do outro, principalmente as dos que se tornam os discriminados bodes expiatórios que carregam a culpa do mal no mundo.

Foi esta a postura, que só pode ser entendida no registro ético da disciplina, que adotei nos meus estudos sobre a criminalidade nas favelas do Rio de Janeiro e que acabou por me apontar outra forma de participação, mais indireta, para completar o binômio fundador da pesquisa etnográfica. Ser vista como uma pessoa justa e "legal" na gíria local, sem dúvida facilita o rapport entrevistador-entrevistado sem que haja a necessidade de adesão ao mundo do outro. Ainda no mesmo registro, mas vinculado ao conhecimento previamente adquirido de como as redes do tráfico de drogas ilegais funcionam, está outra atitude que aproxima traficantes do pesquisador. É aquela que fica clara quando o entrevistador revela que sabe da extensão dessas redes e do envolvimento de pessoas muito longe dali, seja socialmente, por serem de classes sociais superiores, seja espacialmente, por estarem em outras cidades, estados, países. Isto alivia tensões em quem se considera sempre acusado de todos os males decorrentes da atividade ilegal.

Entretanto, se desde o início nas minhas pesquisas usei a abordagem antropológica e os métodos que caracterizam o trabalho de campo etnográfico, quando comecei a estudar quadrilhas de traficantes, deparei-me com problemas éticos e práticos que desconhecia e me envolvi em outras formas de participação que não estavam na interação direta com os "nativos". Recolher material de campo que se baseia na possibilidade de adquiri-lo mediante a interação, o contato face a face, o olho no olho entre o "observador" e outro ser humano dotado de subjetividade - um dos sujeitos da pesquisa tornava-se complicado, perigoso e cheio de surpresas.

Para quem estuda grupos à margem da lei, enfrentando a perseguição da polícia e da justiça, muitas armadilhas e perigos vão aparecer, a maior parte dos quais sem roteiro, sem expectativas já discutidas, sem um código claro de 
como se comportar para adquirir a confiança dos estudados sem ter que se tornar um criminoso como eles. Não há fórmulas para passar adiante. A arte de se relacionar e a criatividade em fazer as perguntas certas a pessoas certas não se aprende em textos acadêmicos, mas na experiência vivida, na atenção redobrada para "saber entrar" e "saber sair", expressões nativas corriqueiras, principalmente nas vizinhanças dominadas por traficantes. Igualmente, a arte de participar de um debate público fora do contexto social imediato da situação de pesquisa também foi surgindo, muitas vezes de forma inesperada, mas nunca involuntária. Foi esta forma de participação política que fui descobrindo junto com as pesquisas de campo realizadas ao longo de quase 30 anos.

A abordagem antropológica é também imprescindível porque fornece a postura epistemológica segundo a qual, na interpretação deste e de outros fenômenos sociais, é preciso romper o preconceito contra os mais fracos e desfavorecidos que tendem a ser apontados como os agentes culpados desta criminalidade. A ruptura contra os estereótipos e as ideias de senso comum, abundantes que são em contextos sociais marcados pelo medo concentrado em certos locais e em certas categorias de pessoas, é fundamental para o sucesso deste empreendimento intelectual. Nesta postura é possível conciliar o estudo do tráfico de drogas ilegais com os princípios éticos da disciplina sem surpresas ou dilemas.

Por isso, o meu interesse nos historiadores da máfia italiana, lidos desde as minhas primeiras pesquisas, que afirmavam que "a máfia nunca foi fenômeno rural, tradicional e de ordem pública paralela na Sicília, mas sempre esteve conectado com o controle ilegal ou ilegítimo de mercados, contratos e negócios tendendo ao monopólio econômico e à vitória eleitoral garantida" (Luppo 2002). Embora nem todos se deem conta, esta criminalidade se constituiu ao término do sistema feudal na Itália, ainda durante o século XIX. Já então misturava promiscuamente negócios e criminalidade, política e favoritismos, clientelismos, fraudes eleitorais e parcialidade na aplicação da lei ou da fraude jurídica. O tráfico de drogas ilegais na Itália, como em outros países do mundo, seria o resultado de profundas mudanças históricas que provocaram hibridismos culturais, rearranjos da propriedade fundiária e jogos políticos complexos, tudo ao fio da navalha de uma violência sem perdão. Este autor recusou o argumento da direita de que os mafiosos seriam os pequenos delinquentes, os bandidos, os insubmissos ao serviço militar, mas não os grandes negociantes nem os políticos que os protegiam, negando igualmente a teoria explicitamente racista que fala da cultura e da raça inferiores para explicar a máfia no sul da Itália.

No Brasil, tive que enfrentar pessoalmente as tentativas bairristas e racistas de explicar o crescimento da violência como resultado da "cultura 
carioca" baseada na malandragem, por extensão, nos favelados (negros, pardos e brancos pobres) da cidade. ${ }^{3} \mathrm{O}$ atraso como metáfora da violência, na verdade, constituiu-se no bode expiatório da ação repressiva do Estado e, para os pesquisadores, no obstáculo epistemológico a ser superado. As consequências foram graves. A repressão policial, apesar das oscilações devidas a mudanças de governo ao longo dos últimos 25 anos, concentrouse nas favelas de algumas regiões, principalmente aquelas localizadas nos subúrbios e na zona norte da cidade, as mais antigas, e onde havia uma população negra carioca descendente de escravos e vinculada às manifestações da cultura afro-brasileira, principalmente o samba.

Como sempre acontece quando o preconceito e os estereótipos de criminosos predominam na imaginação policial, pouca ou nenhuma investigação é feita para desvendar e desmantelar as redes articuladas do tráfico de drogas ilegais e do tráfico de armas, além de muitas outras máfias que controlam negócios de modo ilegal, mesmo quando as mercadorias são legais. Estas redes articuladas ultrapassam barreiras de classe, de perímetros urbanos, de fronteiras estaduais e nacionais, e se imiscuem nos negócios legais, nas instituições do Estado e nos governos. A articulação entre Estado e tráfico de drogas ilegais sempre esteve presente, desde os seus primórdios e sempre foi discutida pelos estudiosos do tema. Não é possível, pois, restringir-se ao varejo, às pontas desta vasta rede que é apenas mais visível entre os mais humildes dos seus membros.

Por isso, a abordagem que adotei em 1980 para estudar a violência urbana, já então apresentada na mídia como o resultado apenas da ação de pequenos e médios delinquentes que habitavam as regiões mais pobres e as favelas da cidade, procurava desconstruir os estereótipos cristalizados nos extremos do espectro ideológico. De um lado, porque a pobreza seria a fábrica de criminosos a encarcerar; de outro, porque a pobreza e a desigualdade fariam dos pobres necessariamente homens violentos, e só o combate à pobreza resolveria o problema do crime. As duas posturas privilegiavam os pobres e ajudavam a cristalizar os estereótipos do criminoso e os preconceitos contra os favelados.

O principal problema desta abordagem, que não só estudava os pobres, mas também os privilegiava como parte da explicação do aumento da violência, era a ausência da conexão entre este inusitado crescimento, notável entre os jovens pobres, e as profundas transformações nas formas de criminalidade que se organizaram em torno do tráfico de drogas, em especial da cocaína, e do contrabando de armas no final da década de 1970. Estes dois negócios, extremamente lucrativos, atravessaram fronteiras nacionais e passaram a mobilizar várias máfias e redes transnacionais com seus agentes pertencentes a classes superiores, médias e também populares. Não se falava 
do que representavam esses negócios no funcionamento de um mercado livre de quaisquer limites institucionais ou morais, com que nem os mais liberais entre os liberais sonharam, justamente por transacionar mercadorias ilegais. O fio da meada ultrapassava o local, o pequeno território da pesquisa de campo, e foi imprescindível segui-lo para entender o que acontecia no pequeno espaço ao qual o pesquisador teve acesso mais direto.

Essa recusa em aceitar novas formas de associação entre criminosos, das quais as mais visíveis e acessíveis estavam nos locais caracterizados como os da pobreza, mudou o cenário não só da criminalidade, mas também da economia e da política no país. Criou-se um círculo vicioso que atrasou em muito a possibilidade de reverter o processo por meio de políticas públicas de prevenção mais eficazes. Além disso, promoveu o progressivo desmantelamento nos bairros pobres do que havia de rica vida associativa, tão importante no direcionamento de suas demandas coletivas e da sua sociabilidade positiva, civilizada, tão importante na formação do capital social e da eficácia coletiva, consideradas, na abordagem ecológica atual, como fundamentais no controle social informal que impede o crescimento da criminalidade (Sampson et alli 1997).

Com isto, espalhou-se entre alguns dos muitos jovens pobres que moram nesses locais um etos guerreiro que os tornou insensíveis ao sofrimento alheio, orgulhosos de infligirem violações ao corpo de seus rivais, negros, pardos e pobres como eles, agora vistos como inimigos mortais a serem destruídos numa guerra sem fim. E, ao final, permitiu abalar a civilidade dos moradores de cidades brasileiras, civilidade que fora construída ao longo de décadas, principalmente nas variadas associações vicinais, inclusive as recreativas escolas de samba, os blocos de carnaval, os maracatus, as folias etc.

Durante anos procurei entender os meandros e os fluxos da extensa rede que toma aspectos mais empresariais e organizados em alguns pontos, o que nos permite perceber a logística eficiente de distribuição de suas principais mercadorias: as drogas ilegais e as armas. Concomitantemente, desde 1986 investigava os efeitos dessa atividade nas formações subjetivas dos jovens nela envolvidos, em especial sua concepção de masculinidade, na fragmentação social e no desmantelamento do associativismo presente nas favelas e nos bairros pobres da cidade. Mais do que uma tipologia do tráfico de drogas ilegais, se tradicional ou empresarial, interessava reconstituir os fluxos e os processos que tornaram tão eficiente e tão lucrativo este empreendimento que se espalhou pelo território nacional, embora com algumas peculiaridades locais, e que acabou por desmantelar o que havia de promessa na parca, mas crescente, participação política encontrada nos bairros populares e nas favelas do Rio de Janeiro nos anos 1980. 


\section{O pragmatismo nas escolhas metodológicas}

O primeiro obstáculo prático que enfrentei quando comecei a estudar quadrilhas de traficantes de drogas ilegais em bairros pobres do Rio de Janeiro foi o das mentiras, um tema bastante discutido e que alguns autores transformaram no cânone que nega a diferença entre versão e verdade. Fez-se necessário outro corte epistemológico: romper com este cânone de que a versão nativa é a verdade.

Esta é a área mais pantanosa da pesquisa sobre o tráfico de drogas ilegais. Primeiro, porque o objeto empírico é uma parte de outra parte de uma sociedade parcial que está incluída em sociedade nacional ainda mais ampla. Segundo, porque a atividade ilegal do crime-negócio é altamente conflitiva: são muitas as versões, porque há aquelas dos que combatem os crimes, aquelas dos que cometem os crimes e aquelas dos que sofrem como vítimas desses crimes. Por fim, a mentira faz parte da clandestinidade das atividades estudadas. São muitas as falsidades necessárias para se manter na atividade: omissões, dissimulações, inverdades são obstáculos presentes na fala dos "nativos" a serem vencidos em todos os momentos na pesquisa. Para ser bem-sucedido na hermenêutica da desconfiança, é preciso diversificar os informantes, em diferentes posições no drama ou nas redes do crime, e ampliar as fontes de dados.

Diante da variedade de depoimentos obtidos e das dificuldades em reconstituir as ações nas quais os entrevistados haviam participado, logo comecei a escrever sobre a necessidade de não confundir as narrativas dos informantes com o real a ser registrado. É que as mentiras são tão mais comuns quanto mais envolvidos eles estejam em atividades ilegais e clandestinas, as quais gostariam de manter longe do conhecimento da polícia e até mesmo da própria família, de vizinhos e colegas.

As barreiras para conseguir depoimentos fidedignos não eram somente as advindas da interação com alguém de fora, de raça e classe superior, de outro sexo, e que poderia até ajudar na sua defesa caso fossem processados, mas também da necessidade primeira de manter este segredo, intrínseco à clandestinidade. O resultado foi que, nas primeiras entrevistas, feitas ainda ingenuamente por mim, a relação entre o falante e o ato da sua fala estava longe da sinceridade e eu nem percebia isto. A descoberta de que mentiam para mim foi possível porque me fiz acompanhar, desde as pesquisas no final dos anos 1980, por assistentes de pesquisa, jovens estudantes universitários moradores do local e que conheciam alguns dos personagens da marginalidade desde crianças. Eles foram meus guias e mediadores, antes de se tornarem assistentes de pesquisa e realizarem entrevistas, segundo o roteiro e a rede de entrevistados previamente planejados. ${ }^{4}$ 
A partir daí, a hermenêutica da desconfiança em relação ao material permaneceu como algo a ser sempre considerado e superado, a fim de que a comunicação entre pesquisadores e os sujeitos envolvidos em crimes, que os faziam alvo de extrema e contínua repressão, e cujas práticas ilegais deveriam permanecer secretas, não se tornasse inútil ou impossível. O cânone antropológico da vinculação entre versão e verdade, já abalado pela polifonia encontrada em pesquisas anteriores, desmoronou definitivamente. A postura relativista ortodoxa, como disse em texto anterior (Zaluar 2004), não mais poderia ser mantida.

O primeiro estratagema que empreguei para superar o entrave da desconfiança e da mentira foi a contratação desses assistentes, que acabaram por fazer a maior parte das entrevistas, segundo o plano traçado por mim. Assim, a relação dual face a face, olho no olho entre entrevistador/ entrevistado foi vivida por terceiros que recolhiam as entrevistas para posterior análise da antropóloga. Escrevi vários textos de cá, para serem lidos por meus pares, destacando a importância e a necessidade da mediação desses terceiros. E esta mediação deixava também suas marcas nas falas recolhidas pelos assistentes, segundo as perguntas formuladas, por partilharem com os entrevistados um código de significados e regras de comunicação do qual eu permanecia excluída. ${ }^{5}$ Era isto que garantia mais rapport à interação, mais confiança entre entrevistador e entrevistado, maior confiabilidade nas respostas obtidas e mais distância da pesquisadora principal que era eu.

As entrevistas tornaram-se por isso um quebra-cabeça de significados despedaçados, e os dados ali contidos, fragmentos cujo sentido eu deveria buscar entre os ditos de entrevistados e entrevistadores. Concluí que os fatos não são apenas construídos teoricamente e conquistados na prática sedutora do pesquisador, mas são também frutos das condições estrategicamente montadas pelo pesquisador, mesmo quando não é ele quem está lá. E esses fatos ou dados são mais claramente fragmentos de textos, no caso, fragmentos de discursos dirigidos a outrem. Para decifrá-los, como eu não estava "lá", nem "perto", nem "dentro" e não me deixara envolver pelo fascínio da conversação que prende a atenção dos interlocutores no entendimento do conteúdo, dos significados do dito, podia visualizar melhor a situação da entrevista em suas condições de possibilidade (Zaluar 2004). De fora, lendo um depoimento tão mais "de dentro" do que eu própria jamais conseguiria, atingia mais facilmente a distância necessária para observar as figuras de retórica, os padrões discursivos, os pontos de referência compartilhados nas conversas das quais não participei. Entretanto, o individual, o idiossincrático, o criativo, o perceptivo e o afetivo presentes nas narrativas dos nativos também surgiam, sem perderem seu aspecto social, de formação subjetiva. 
A fusão de horizontes, pretendida no projeto hermenêutico da interpretação, nunca se completava porque as diferenças e as novidades davam-lhe um caráter de caminhos paralelos e abertos, incompletos, definitivamente marcados pelo gênero, pela idade, pela biografia pessoal, pela história.

\section{Convivendo e conversando com o perigo}

Não há como negar que o estudo de tal objeto empírico, povoado de sujeitos envolvidos em atividades ilegais e violentas, vigiado por policiais violentos que apresentam uma dupla face no tratamento do tráfico de drogas ilegais, é muito perigoso. Enfrentei, algumas vezes sem nem perceber, certas situações em que agressões graves poderiam ter acontecido.

Logo que cheguei à Cidade de Deus, em 1980, sem ter alcançado ainda a Praça Matusalém onde conheci o drama de Manoel Galinha e seus parceiros, procurei uma forma de me inserir na vizinhança e pessoas em quem me apoiar. Um deles me foi indicado por um fotógrafo que publicava no principal jornal do Rio de Janeiro fotos de violência feitas ali. Este jovem me sugeriu ir assistir a um ritual religioso que acontecia durante a noite no conjunto habitacional. Fui dirigindo o meu carro, acompanhada de dois amigos, e estacionei perto da sua casa para irmos a pé até ao local. Mas o jovem não nos dizia onde seria o ritual nem quando começaria. Seus vizinhos acompanhavam nossa conversa com um interesse que me chamou a atenção. Quando resolvi ir embora, percebi que o carro não arrancava mais. Imediatamente um senhor, vizinho do jovem, interveio e lhe disse rispidamente para colocar os cabos da bateria que ele havia arrancado sem que nós percebêssemos, ou seja, os vizinhos viram e impediram o crime, o que ainda era possível então, certamente mais um dos muitos assaltos ou sequestros que aconteciam na cidade.

Posteriormente, um dos meus assistentes de pesquisa, que morava em Cidade de Deus, me afirmou que eu quase havia sido estuprada numa das visitas à casa de um jovem de quem achava ter ficado amiga na primeira fase da pesquisa, quando andava sozinha pelo conjunto no início dos anos 1980. Eu teria escapado - pensei ao recordar a situação — porque passei um dos meus gravadores para que ele entrevistasse colegas e por ter emprestado um livro que ele gostaria muito de ler. Anos mais tarde, este mesmo rapaz, já manejando a ferramenta da Internet, me enviou uma mensagem. Nas conversas telefônicas que se seguiram, negou veemente que tivesse contado tais fatos ao meu assistente de pesquisa. Como ele tinha o mesmo nome que o personagem do evento anterior, eu jamais ficarei sabendo exatamente o 
que aconteceu e de quantos perigos escapei pelo simples fato de ter sido sempre coerente e explícita quanto aos objetivos da pesquisa.

E isso foi tudo. Nunca fui assaltada, agredida, ofendida ou maltratada nos muitos anos que passei fazendo pesquisa de campo neste conjunto. $\mathrm{Na}$ verdade, sentia-me mais protegida quando estava dentro da favela do que quando andava pelas ruas do Centro ou dos bairros de classe média do Rio de Janeiro. ${ }^{6}$ Mas estávamos nos anos 1980, ainda nos primórdios do tráfico de drogas ilegais associado ao tráfico de drogas e de armas, que foi se tornando cada vez mais violento e cruel com o passar dos anos e a consolidação dos comandos que os dirigiam desde as prisões, principalmente em São Paulo e no Rio de Janeiro. Nas décadas seguintes, os cuidados tiverem de ser redobrados para entrar na favela e a consciência do perigo, com o consequente sentimento de medo, passou a ser a companhia cotidiana dos envolvidos no trabalho de campo das pesquisas seguintes.

Os maiores perigos que pesquisadores enfrentam no campo continuam sendo os riscos de confrontos efetuados pelo controle militar das comunidades visitadas, sempre que ocorre uma guerra pelo comando do morro entre a facção instalada e a facção invasora ou, como acontece no Rio de Janeiro agora, entre a Polícia (inclusive com suas organizações paramilitares ilegais, as milícias) e os traficantes. Pesquisadores e demais profissionais que trabalham em vários centros de atendimento existentes nesses locais continuarão a observar as marcas deixadas por traficantes e policiais em paredes, janelas, portas, sem saberem muito bem como lidar com a eventualidade de um tiroteio em tempo real. Um dos primeiros aprendizados passa a ser o do código de prenúncios e os avisos explícitos que moradores recebem para se recolher ou não aparecer em tais locais. Indagar se é possível entrar a cada dia, a cada hora, saber como entrar e saber como sair sem perturbar ou incomodar os traficantes que dominam as comunidades é procedimento imprescindível para quem quer levar a termo o estudo e sobreviver.

Assim como no Brasil, os relatos de pesquisadores que estudaram traficantes em outras partes do mundo estão ainda mais cheios das desventuras e das situações de risco por que passaram, chamando a atenção para outra postura imprescindível, esta mais de ordem utilitária, em registro prático-instrumental. Manter a calma e esconder o medo passa a ser um procedimento do kit sobrevivência. Bruce Jacobs (1998:165) resume esta postura assim: ${ }^{7}$

[...] Como outros pesquisadores observaram, a preocupação com a "violência pode levar os etnógrafos a parecerem apavorados, ou a reagirem de forma inadequada a situações e perigos comuns na rua [...] Um comportamento medroso é facilmente percebido por pessoas violentas" e pode muitas vezes 
levar à própria violência. Assim, Berk e Adams frisam a importância de manter a calma quando ameaçado: "O investigador será constantemente observado e testado pelas próprias pessoas que ele está estudando. Isto é mais verdadeiro ainda (para) os delinquentes que [...] valorizam a coragem diante do perigo". Deve se lembrar aqui que o perigo é "inerente" ao trabalho de campo com infratores da lei, "se não por outra razão, porque há sempre a possibilidade de perigosos mal-entendidos culturais entre pesquisadores e objetos de pesquisa". Isto é mais verdadeiro ainda em relação à pesquisa entre vendedores de crack na rua, que usam cotidianamente a violência ou as ameaças de violência para conseguir cumplicidade [...].

Ainda no registro utilitário, manter a assimetria entre o sujeito observador e o sujeito observado, entrevistador e entrevistado, pesquisador e pesquisado, especialmente quando os últimos destes pares de interação estão ou estiveram no mundo criminal, portanto cercados de segredos e silêncios quanto ao que se passa no mundo de ilegalidades, pode produzir o efeito de tornar mais prováveis revelações e confissões. Ao contrário do que dizem os que advogam a identificação e a assimilação entre entrevistador e entrevistado, é a própria distância que facilita a interlocução e as confissões sinceras de ambas as partes.

Foi enquanto mulher que vislumbrei uma possível interpretação inovadora nas análises feitas sobre a criminalidade no Brasil. A repetição de certos arranjos e associações simbólicas relacionando o uso da arma de fogo, o dinheiro no bolso, a conquista das mulheres, o enfrentamento da morte e a concepção de um indivíduo completamente autônomo e livre "gritavam" aos meus olhos que as práticas do mundo do crime vinculavam-se a um etos de masculinidade exacerbado, exagerado, centrado na ideia de um chefe despótico cujas ordens não poderiam ser desobedecidas ${ }^{8}$ (Zaluar 1989 e 1990). Sem discordâncias nem oposições, a paz do cemitério não conduzia às confissões sinceras nem às revelações audazes. Era necessário continuar a catá-las de muitas maneiras.

Mesmo assim, o afastamento do pesquisador, que não é da vizinhança, nem da classe social, nem do sexo do interlocutor, pode estimular as confidências. É claro que isto só funciona quando vem acompanhado do esclarecimento quanto aos objetivos científicos do estudo, quanto à manutenção do anonimato, ao desinteresse de quem fez o quê substituído pelo foco em como e por que tantos fizeram. Em outras palavras, o afastamento deve ser duplo ou triplo: além de se distanciar dos próprios investigados, é preciso deixar claro que o pesquisador não tem os métodos e os objetivos da investigação policial que procura os suspeitos a serem acusados em inquéritos e processos judiciais, 
assim como os de jornalistas, que buscam personagens importantes para narrar em notícias selecionadas por serem de interesse dos leitores. A imagem do pesquisador não pode ser confundida nem com a do investigador de polícia, nem com a do jornalista, figura também temida por não ter os mesmos compromissos científicos e por publicar muito rapidamente as "descobertas" ou "furos" de suas entrevistas, ${ }^{9}$ dos quais os nomes dos envolvidos fazem parte. Para convencer que não é e não age como um jornalista ou um policial, o pesquisador não precisa se identificar com o criminoso a ponto de passar a participar de suas atividades ou se confundir com ele.

Como mais um estratagema para soltar o verbo dos entrevistados, portanto ainda no registro utilitário, está o emprego de grupos focais ou de entrevistas coletivas com mais de dois entrevistados. Nos primeiros, realizados segundo técnicas já estabelecidas, reúnem-se de cinco a oito indivíduos em uma mesma sessão para observar a interação entre eles e registrar todas as suas reações e diálogos a partir das perguntas feitas coletivamente. Usei esta técnica na pesquisa em que foram comparados os estilos de tráfico e de uso de drogas ilegais em três bairros do Rio de Janeiro (Zaluar 2001).

No final da década de 90, resolvi ampliar o campo das pesquisas sobre o tráfico de drogas comparando três bairros da cidade do Rio de Janeiro, o que me permitia usar os dados estatísticos e discutir como a pobreza e a desigualdade social se combinam com os estilos de tráfico e de uso de drogas. Nesta comparação foram utilizadas várias fontes de dados. As estatísticas oficiais da polícia foram coletadas para conhecermos a incidência de alguns crimes, tidos como vinculados ao tráfico de drogas ilegais e às dívidas que os compradores de suas mercadorias e serviços contraem, tais como roubos e furtos de autos, outros roubos e furtos; ou então os que são resultado dos métodos de resolução de conflitos internos, como o homicídio, também denominados homicídios sistêmicos. Os dados do IBGE sobre as regiões administrativas onde estão localizados os bairros que, aliás, lhes dão o nome, permitiram a comparação demográfica, a socioeconômica e a de atividades econômicas que poderiam ajudar a entender as condições de vida nesses bairros, especialmente de seus jovens, principais protagonistas e vítimas dos crimes violentos, sobretudo do homicídio.

Por fim, foi necessário estudar a organização do tráfico em cada um desses locais, escolhidos justamente por terem inúmeros estabelecimentos legais de lazer e boemia, além de várias favelas. As ligações entre os traficantes do asfalto e da favela, assim como entre os usuários e esses traficantes foram objeto de investigação etnográfica em cada um dos bairros escolhidos.

Procurei trazer também as outras vozes dos espectadores-vítimas na tragédia particular de uma guerra sem sentido e sem fim, que ocorre nas 
mais ricas e maiores cidades brasileiras, divididas também pelos efeitos do fundamentalismo cristão que re-encantou o mal e transformou as mais importantes e difundidas manifestações da cultura afro-brasileira em manifestações do demônio.

No trabalho de campo, a observação silenciosa e discreta, junto com as entrevistas aprofundadas que seguiam um roteiro aberto, mostrou ser o método essencial para revelar as redes de tráfico e os estilos de consumo numa situação de pesquisa repleta de riscos e perigos. O objetivo era entender os processos sociais objetivos, e não nomes de pessoas, principalmente na distribuição das drogas ilegais, assim como as formações subjetivas que constituíram o consumo, revelando o simbolismo que as caracterizam para diversos tipos de usuários. O pressuposto teórico era o de que todos os dados advêm da relação social entre os pesquisadores e os sujeitos que se constituem em seu objeto de estudo, o que exige reciprocidade e confiança. Estávamos particularmente interessados na formação de um etos guerreiro entre jovens atraídos pelo tráfico, assim como na formação subjetiva da masculinidade em vários outros estilos de lazer (como os bailes funk e charme, ou de esportes como o jiu-jitsu e as torcidas organizadas do futebol).

No final da pesquisa, foram montados três grupos focais em cada bairro, método igualmente fundamental para revelar os mecanismos diferenciados do tráfico de drogas em cada bairro, bem como as distintas disposições e concepções de masculinidade. O objetivo era entender os processos sociais existentes no tráfico, ou seja, a dinâmica das relações entre fornecedores de armas e drogas, traficantes e usuários, assim como as formações subjetivas reveladas no simbolismo e nos rituais das interações entre os atores. Os contatos para entrevistas foram feitos seguindo a rede de conhecidos dos usuários ou nos locais de lazer escolhidos para a observação silenciosa. Desse modo, muitas definições e imagens e vários significados contextuais do crime, do desvio, da droga, da polícia, do bairro, das diversas atividades de lazer, das relações entre os usuários, entre eles e os traficantes, entre todos e a polícia foram transmitidos pela observação direta, por conversas informais depois registradas e pelos relatos de experiências de nossos informantes.

A comparação entre os bairros no que se refere aos estilos de uso não se mostrou importante para se entenderem as diferenças nas incidências de alguns crimes, especialmente homicídios, roubos e furtos, apontados como relacionados ao tráfico de drogas. Já os estilos de tráfico e a maneira pela qual tanto repassadores quanto usuários se relacionam com os "donos da boca" ou os "donos do morro" revelaram-se de fundamental importância.

Todas as informações foram obtidas in loco ou na situação artificial, mas não menos necessária, do grupo focal montado na universidade. Quando in 
loco, os pesquisadores testemunharam tiroteios e tiveram que se esconder junto com moradores não envolvidos. Isto não teve nenhum efeito no seu rapport com os últimos, porque deixou de ser um acontecimento extraordinário. Passou a ser o corriqueiro, o usual, parte do cotidiano de todos que moram nas favelas dominadas por traficantes.

A última pesquisa feita no âmbito das atividades do NUPEVI foi aquela montada em 2007 junto com um aluno que queria estudar as saídas do tráfico, mais do que as entradas para ele, já tão discutidas na literatura. O objeto empírico era a reconstrução das trajetórias de indivíduos que abandonaram o tráfico para entender os diferentes significados e padrões da saída.

Montei, a partir de um personagem da primeira pesquisa que fiz em Cidade de Deus, protagonista da guerra romanceada e filmada com repercussão internacional, uma rede de ex-prisioneiros que, como ele, não desejavam mais voltar ao tráfico de drogas. Nas entrevistas coletivas, técnica criada por mim para realizar esta pesquisa, este personagem atuou ao mesmo tempo como recrutador que convocava os demais, informante-chave e mediador na interlocução entre entrevistados e entrevistadores. Embora tivessem sido feitas algumas entrevistas individuais, os grupos assim montados nunca ultrapassaram quatro pessoas, para que fosse possível aprofundar as histórias de vida de cada um. O informante-chave fazia a mediação para esclarecer os pontos obscuros, as possíveis deturpações ou os mal-entendidos devidos ao linguajar carregado de gírias etc. Conhecedor dos truques e das ciladas do seu meio, não deixava passar mentiras nem bazófias comuns entre os que vivem situações de perigo e de ilegalidade.

Como acontece no grupo focal, a interlocução com o entrevistador pode desencadear a conversa independente entre os entrevistados, tanto mais interessante quanto mais discordarem um do outro, desmentirem fatos, esclarecerem dúvidas e aprofundarem o conhecimento de cada um a respeito do que sabem sobre as muitas atividades reunidas na expressão "tráfico de drogas ilegais". Os que gostam de exagerar seus feitos, ou de esconder suas responsabilidades costumavam ser imediatamente corrigidos pelos demais presentes, em especial pelo informante-chave, que permaneceu como um membro da equipe de entrevistadores, formada por mim e um doutorando, Luiz Fernando Almeida Pereira (2008), que escreveu sua tese de doutorado com base no material desta pesquisa. A dupla inserção deste informantechave, baseada na confiança nele depositada pelos dois lados da situação de pesquisa, foi fundamental para que o rapport estabelecido criasse entendimento entre os interlocutores e distendesse os receios de denúncia, traição ou "escama", usuais entre os que penetram no mundo da ilegalidade, vigiada e punida por agentes da lei nem sempre agindo de forma legal. 
A maior vantagem desta pesquisa foi que, pelo arranjo das entrevistas coletivas na própria universidade onde se localiza o NUPEVI, os entrevistadores, eu e Luiz Fernando não tivemos que correr os riscos de andar pelas vielas das favelas ou ruas dos bairros em que traficantes têm conhecidos pontos de venda, e de onde dominam territórios maiores. Pelos métodos de escolha dos entrevistados intermediados pelo informante-chave, também não corríamos o risco de ser confundidos com policiais ou jornalistas.

A pesquisa em entrevistas de pequenos grupos, marcadas na universidade, resolvia, portanto, os principais problemas da pesquisa no perigo: o acesso e o controle das mentiras contadas. Ir até a universidade significava estar em uma sala com o gravador ligado e consciente de que deveria responder a perguntas sobre atividades criminosas. Ir até lá em pequeno grupo previamente conhecido era um exercício de interdependência e interlocução entre os entrevistados pois, como sujeitos e objetos na entrevista, poderiam estabelecer uma vigilância mútua sobre o que era narrado por cada um a seu tempo, além de falar de suas próprias experiências e interpretações.

Nesta pesquisa, seguimos os mesmos procedimentos éticos das anteriores: manter o anonimato do entrevistado e o sigilo de algumas das informações que não queriam tornar públicas. Entender a rede de relações, conflitos e dilemas dos entrevistados não pode ser confundido com oferecer denúncia a um órgão repressor, outro perigo apontado pelos pesquisadores em sociedades com um sistema judicial muito presente, que exige de alguns deles tal denúncia em função de seu conhecimento das atividades criminosas.

\section{Generalizações impossíveis e comparações necessárias}

Após a primeira tentativa de aumentar o escopo das investigações e permitir a comparação entre três bairros do Rio de Janeiro, nos últimos dois anos resolvi ampliar ainda mais o campo de visão proporcionado pela pesquisa quantitativa ao realizar um survey - o de vitimização - em toda a cidade do Rio de Janeiro. Para isso tive que recorrer aos métodos quantitativos mais usados por sociólogos e epidemiólogos. Adquiri um mapa muito mais abrangente, mais preciso e mais interessante para quem já tinha o conhecimento etnográfico dessa dinâmica do tráfico de drogas em diversos bairros da cidade. Conheci as profundas diferenças entre as áreas de planejamento, as regiões administrativas, os bairros e as vizinhanças estudadas. Descobri que é necessário, pois, englobar para ter uma visão do conjunto da cidade e, simultaneamente, localizar ainda mais, apertar o foco nas diversas regiões 
existentes nelas, pois as diferenças são marcantes. Agregar e desagregar são também dois movimentos igualmente necessários no trato dos dados estatísticos ou "quantitativos", que podem ser iluminados pelos dados das pesquisas etnográficas, também chamados "qualitativos".

O curioso é que as situações de maior perigo, inclusive de sequestro de um pesquisador, foram vividas na pesquisa de vitimização nos bairros de classe média ilhados pela pobreza circundante nos subúrbios ou na zona oeste da cidade. Descobri que é mais perigoso entrar na casa de alguém apavorado com os altos índices de criminalidade da área em que vive do que conseguir entrar em favela dominada por traficante. Depois de uma negociação inicial e com a ajuda de "guia", a pesquisa na favela tornavase sem imprevistos, contanto que se seguissem as regras de aviso sobre os tiroteios sempre possíveis em tais locais.

Foi esta pesquisa, no entanto, que me permitiu entender a dinâmica diferenciada do tráfico de drogas e da repressão policial nas diversas áreas da cidade e que me apontou novos problemas e objetos de pesquisa. A um deles chamei de "o paradoxo da cidade" — por que justamente na área que apresentava os mais altos percentuais de sociabilidade e confiança nos vizinhos havia maiores proporções de vitimização por violências, principalmente as resultantes de tiroteios, com vizinhos e amigos assassinados?

E nada do que descrevi em etnografias do crime fará sentido se não houver consciência de que o alcance das pesquisas etnográficas no Brasil sobre o tema do tráfico de drogas ilegais tem sido limitado aos grupos que operam nas pontas das redes, portanto, aos de menor importância. Para preencher os vazios e ver de longe a floresta, o pesquisador de campo precisa daqueles de cujas atividades e identidades ele teve primeiro que se afastar: policiais, promotores e jornalistas. As investigações policiais, baseadas na inteligência, e o jornalismo científico, que cata fatos entrevistando personagens importantes desses dramas aqui e alhures, complementarão os dados que a pesquisa etnográfica não consegue obter. Aplicados os devidos cuidados e filtros ao lidar com tais fatos, esta complementação é imprescindível para realizar o percurso aqui discutido.

Esta é a marca da antropologia do contemporâneo praticada em sociedades cada vez mais diferenciadas e em um mundo que nunca foi tão globalizado, exigindo, portanto, a multiplicidade de fontes de dados, de planos de abordagem e de perspectivas teóricas. Como Rabinow sugere (2008), é preciso averiguar o que acontece em outras disciplinas, ser cauteloso e paciente enquanto inventamos novos conceitos e realizamos diligentemente novas pesquisas. A antropologia terá que dividir com outros ramos do conhecimento as verdades sobre os seus objetos, perdendo a amplitude e a 
ambição da etnografia tradicional sobre seus objetos tradicionais. Mas ainda lhe restará o que só proporcionam a observação participante - enquanto for possível participar sem negar de onde vem e quem é o observador, com suas similitudes e diferenças éticas - e o registro da interação observadorobservado marcada, às vezes, por escolhas trágicas.

Recebido em 13 de abril de 2009

Aprovado em 24 de junho de 2009

Alba Zaluar é professora titular de antropologia do Instituto de Medicina Social, UERJ. E-mail: <amz84@globo.com>

\section{Notas}

* Parte deste texto foi primeiramente apresentada em Seminário Internacional sobre o Crime Organizado, realizado no Núcleo de Estudos da Violência, USP, em 2007, com o título "Pesquisando Crime Organizado", cujos anais ainda não foram publicados. Foi revisto, aumentado e recortado para a discussão sobre a etnografia do crime.

${ }^{1}$ No original: “[...] there is nothing better than initiatory immersion and even moral and sensual conversion to the cosmos under investigation [...] It makes possible for the sociologist to appropriate in and through practice the aesthetic, ethical and cognitive schemata that those who inhabit that cosmos engage in their everyday deeds".

${ }^{2}$ No original: "[...] by becoming a gang member I was often forced and expected to adopt a number of particular behaviour patterns, some of which were in fact compounded by my being a chele pandillero [...] This included having to participate in a range of violent and illegal activities, including gang wars, thefts, fights, beating, fencing and conflicts with the police, as a result of which I underwent a number of things that I could have done without, including being attacked, threatened, beaten up, knifed, shot at and thrown out of a moving car."

${ }^{3}$ Certa vez, assim que cheguei a Belo Horizonte para participar de um seminário internacional sobre violência, fui interpelada por policiais militares mineiros 
que, de dedo em riste, acusavam um famoso bandido fluminense - Fernandinho Beira Mar - de ser o mandante do assassinato de um promotor de justiça que havia morrido na véspera naquela cidade. Surpresa, perguntei: mas já terminou a investigação? A resposta foi ainda mais enfática: os bandidos do Rio estão vindo para cá e aumentando a criminalidade. Semanas depois, a investigação revelou que o promotor morto era carioca, o executor era um suboficial da PM de Minas Gerais e os mandantes eram donos de postos de gasolina, mineiros, envolvidos na máfia que o promotor investigava.

${ }^{4}$ Os resultados desta pesquisa estão em meu livro Condomínio do diabo, publicado em 1994.

${ }^{5}$ Esta foi uma das razões que me levaram a incentivar e a ajudar Paulo Lins a escrever o seu romance etnográfico — Cidade de Deus — durante seis dos nove anos em que permaneceu na equipe de pesquisa que eu coordenava. Além de bolsa de estudo, Paulo teve acesso a todo o material já coletado nas pesquisas em que participou, como também da primeira que fiz em Cidade de Deus na praça onde morou e morreu Manoel Galinha, pesquisa feita muito antes que eu o conhecesse.

${ }^{6}$ Os resultados e as interpretações desta primeira pesquisa de campo solitária em Cidade de Deus estão na minha tese de doutorado, A máquina e a revolta, publicada em 1985 pela Editora Brasiliense.

${ }^{7}$ Tradução de Patrícia Farias.

${ }^{8}$ Ao mesmo tempo, a leitura da teoria sobre formação subjetiva do etos guerreiro (Elias 1993) ajudou-me a interpretar o que percebera.

${ }^{9}$ Entrevistados contavam como os traficantes que falaram demais a jornalistas que publicaram livros sobre o tráfico de drogas no Rio de Janeiro, citando seus nomes ou deixando muitas pistas para que fossem identificados, acabaram mortos na prisão pelos seus comparsas revoltados com a traição. 


\section{Referências bibliográficas}

BOURGOIS, Pierre. 1995. In search of respect: selling crack in the barrio. Cambridge: Cambridge University Press.

CLIFFORD, James (ed.). 1986. "Introduction". In: Writing cultures. Berkeley: University of California Press. pp. 1-27.

ELIAS, Norbert \& DUNNING, Eric. 1993. Quest for excitement, sport and leisure in the civilizing process. Oxford: Oxford University Press.

EVANS-PRITCHARD. 1951. Social anthropology. London: The Free Press.

FARRELL, Jeff \& HAMM, Mike. 1998. "True confessions: crime, deviance and field research". In: Jeff Farrell \& Mike Hamm (eds.), Ethnography at the edge: crime, deviance, and field research. Boston: Northeastern University Press. pp. 2-19.

GEERTZ, Clifford. 1983. Local knowledge. London: Fontana.

- 1988: Works and lives, the anthropologist as author. Stanford: Stanford University Press.

JACOBS, Bruce. 1998. "Researching crack dealers: dilemmas and contradictions". In: Jeff Farrell \& Mike Hamm (eds.), Ethnography at the edge - crime, deviance, and field research. Boston: Northeastern University Press. pp. 160-177.

LUPPO, Salvatore. 2002. História da máfia. Editora UNESP: São Paulo.

MALINOWSKI, Bronislaw. 1975. "Introdução aos Argonautas do Pacífico Ocidental". In: Alba Zaluar Guimarães (ed.), Desvendando máscaras sociais. Rio de Janeiro: Ed. Francisco Alves. pp. 39-62.

MARCUS, George \& FISCHER, Michael. 1986. Anthropology as cultural critique. Chicago: University of Chicago Press.

PEREIRA, Luiz Fernando A. 2008. Meninos e lobos. Trajetórias de saída do tráfico na cidade do Rio de Janeiro.
Tese de doutorado, Instituto de Medicina Social, IMS/UERJ.

RABINOW, Paul. 2008. Marking time: on the anthropology of the contemporary. Princeton: Princeton University Press.

RODGERS, Dennis. 2007. "Joining the gang and becoming a broder: the violence of ethnography in contemporary Nicarágua". Bulletin of Latin American Research, 26(4):444-461.

SAMPSON, Robert J. et alli. 1997. "Neighborhoods and violent crime: a multilevel study of collective efficacy". http://www.wjh.harvard.edu/soc/faculty/sampson/articles/1997_Science.pdf

VERNANT, Jean Pierre. 1992. Mito e religião na Grécia Antiga. Campinas: Papyrus.

WACQUANT, Loïc. 2004. Body and soul: notebooks of an apprentice boxer. Oxford: Oxford University Press.

ZALUAR, Alba. 1985. A máquina e a revolta. São Paulo: Editora Brasiliense. . 1989. "Nem líderes nem heróis" Revista Presença, 13, também publicado em Zaluar, Alba (org.). 1992. Violência e educação. Rio de Janeiro: Cortez Editora. pp. 19-36.

. 1990. "Teleguiados e chefes". Religião e Sociedade, 15(1):54-67. - 1994. Condomínio do diabo. Rio de Janeiro: Editora da UFRJ. . 2001. "Violence à Rio de Janeiro: styles de loisirs, de consommation et de trafic de la drogue". Revue Internationale des Sciences Sociales, 169:407-417 ou "Violence in Rio de Janeiro: styles of leisure, drug use and trafficking". International Social Science Journal, 169:370-378. - 2004. Integração perversa. Rio de Janeiro: Editora FGV. 


\section{Resumo}

O artigo discute a questão do relativismo cultural que assume caráter polêmico na passagem do milênio, principalmente nas divergências surgidas sobre o que fazer diante dos dilemas postos pelos novos sujeitos-objetos e dos impasses advindos da difusão planetária de posturas universalistas. Novos problemas e dilemas éticos se antepuseram ao fazer antropológico: o que são direitos humanos e qual o seu alcance entre nativos não ocidentais; quem conta como pessoa humana e quem deve ser ouvido nas sociedades estudadas; como lidar com a opressão de pessoas no interior das "sociedade dos nativos" quando os opressores são também nativos. Na etnografia do crime, é possível e preciso o mergulho no mundo do outro a ponto de virar nativo? A antropologia do contemporâneo, praticada em sociedades cada vez mais diferenciadas e em um mundo que nunca foi tão globalizado, exige a multiplicidade de fontes de dados, de planos de abordagem e de perspectivas teóricas, averiguando o que acontece em outras disciplinas, sendo cauteloso e paciente na invenção de novos conceitos e novas pesquisas.

Palavras-chave Etnografia, Ética de pesquisa, Relativismo cultural, Participação, Distanciamento

\section{Abstract}

The article discusses the question of cultural relativism, an issue that has become increasingly polemical at the turn of the millennium, especially with the diverging opinions on how to respond to the dilemmas posed by the new subjects-objects and the impasses generated by the global diffusion of universalist stances. New ethical problems and dilemmas prevene anthropological practice: what are human rights and what are their reach among non-western natives; who counts as a human person and who should be heard in the societies under study; and how to deal with the oppression of people within the 'native societies' when the oppressors are themselves natives? In the ethnography of crime, is it possible or necessary to submerge oneself in the world of the other to the point of turning native? The anthropology of the contemporary, practiced in increasingly differentiated societies and in an ever more globalized world, demands a multitude of data sources, approaches and theoretical perspectives, verifying what is happening in other disciplines, and remaining cautious and patient in the invention of our concepts and new research.

Key words Ethnography, Research ethics, Cultural relativism, Participation, Distancing 